\title{
X-ray diffraction studies of phase transformations between tetragonal and cubic phases in the $\mathrm{BaSn}_{x} \mathrm{Ti}_{1-x} \mathrm{O}_{3}$ system
}

\author{
WEN-KU CHANG, SHY-FENG HSIEH, YUAN-HAUN LEE \\ Graduate Institute of Materials Science and Engineering, National Taiwan University, \\ Taipei, Taiwan \\ KUAN-NENG CHEN, NAN-CHUNG WU \\ Department of Materials Science and Engineering, National Cheng-Kung University, \\ Tainan, Taiwan
}

\author{
A. A. WANG \\ Chemical Engineering Department, Nan Ya Junior College, Chung Li, Taiwan
}

\begin{abstract}
$X$-ray powder diffraction has been used to investigate the cubic-tetragonal phase transformation and lattice constant in a $\mathrm{BaSn}_{x} \mathrm{Ti}_{1-x} \mathrm{O}_{3}$ system $(x=0.0-0.2)$ at room temperature. The existing regions of tetragonal phase were strongly influenced by the amounts of tin (from $x=0.0-0.1$ ). The mass fraction of the tetragonal phase decreases as substitution of tin for titanium increases until $x=0.1$, while the mass fraction of the cubic phase increases simultaneously. The lattice constant of cubic phase and the cube roots of the unit-cell volumes of tetragonal phases indicate linear relations with the amounts of tin. (C) 1998 Chapman \& Hall
\end{abstract}

\section{Introduction}

Barium titanate ceramics have exceedingly high dielectric constants with low dissipation factors and have been widely used as capacitor materials [1,2]. However, the high temperature coefficient of dielectric near the Curie point will be influenced by the extent of application. Various reports $[3,4]$ have suggested that the Curie temperature of barium titanate could shift to other temperatures by the substitution of the solid solution of other perovskite materials having structures similar to barium titanate.

Among the modified $\mathrm{BaTiO}_{3}$ compositions, the $\mathrm{Ba}(\mathrm{Sn}, \mathrm{Ti}) \mathrm{O}_{3}$ system has attracted considerable attention. The partial replacement of titanium by tin is reported [5] to improve the dielectric behaviour, while systematically decreasing the Curie temperature as the tin concentration increases. Drexler and Schat [6] have analysed the relationship between the Curie temperature and dielectric constant in the $(\mathrm{Ba}, \mathrm{Ca})$ $(\mathrm{Ti}, \mathrm{Sn}) \mathrm{O}_{3}$ system.

Other scientists believe that the characteristic of dielectric constants are strongly influenced by either the phase transformations of the crystal structure or the transformations between ferroelectric and paraelectric near the Curie temperature. Yoon et al. [7] refined and analysed the X-ray diffraction (XRD) data by one phase (tetragonal phase) in the $\left(\mathrm{Ba}_{0.9} \mathrm{Ca}_{0.1}\right)$ $\left(\mathrm{Ti}_{1-x} \mathrm{Sn}_{x}\right) \mathrm{O}_{3}$ system to determine their lattice constants and unit-cell density. Calos et al. [8] studied the structural and dynamic changes of the $\left(\mathrm{A}_{1-x} \mathrm{~Pb}_{x}\right) \mathrm{TiO}_{3}$
$(\mathrm{A}=\mathrm{Ca}, \mathrm{Sr}, \mathrm{Ba})$ perovskites by $\mathrm{XRD}$ and Raman spectroscopy. The crystallography and microstructure of $(\mathrm{Ba}, \mathrm{Ca}) \mathrm{TiO}_{3}$ ceramics prepared using $(\mathrm{Ba}, \mathrm{Ca}) \mathrm{CO}_{3}$ were studied by Tiwari et al. [9].

In this study, the lattice constant and phase transformation were investigated in relation to the amounts of tin. The powder XRD data of $\mathrm{BaSn}_{x} \mathrm{Ti}_{1-x} \mathrm{O}_{3}$ $(x=0.0-0.2)$ solid solutions were refined in the cubic and tetragonal phases simultaneously by the multiphase Rietveld refinement method.

\section{Experimental procedure}

\subsection{Specimen synthesis}

The $\mathrm{BaTiO}_{3}$ and $\mathrm{BaSnO}_{3}$ ceramics were also synthesized by solid-state reaction from $\mathrm{BaCO}_{3}, \mathrm{TiO}_{2}$ and $\mathrm{SnO}_{2}(99.9 \%)$ powders. Each batch was wet ballmilled for $10 \mathrm{~h}$ with water as the mixing agent and then dried completely. The mixed powders of $\mathrm{BaTiO}_{3}$ and $\mathrm{BaSnO}_{3}$ were calcined for $2 \mathrm{~h}$ at $1200^{\circ}$ and $1400{ }^{\circ} \mathrm{C}$, respectively. It is important that the calcined powders of $\mathrm{BaTiO}_{3}$ and $\mathrm{BaSnO}_{3}$ were confirmed as solid solutions by XRD analyses. The samples of $\mathrm{BaSn}_{x} \mathrm{Ti}_{1-x} \mathrm{O}_{3}(x=0-0.2)$ used for data collection were all prepared from $\mathrm{BaTiO}_{3}$ and $\mathrm{BaSnO}_{3}$ powders under various ratios. The mixed powders were combined with $1 \mathrm{wt} \%$ PVA binder, sieved to 80-120 mesh and pressed into pellets $(12 \mathrm{~mm}$ diameter and $0.8 \mathrm{~mm}$ thick) by pressing at $25-30 \mathrm{~kg} \mathrm{~cm}^{-2}$. Each sample was calcined in air at $600{ }^{\circ} \mathrm{C}$ for $2 \mathrm{~h}$ in order to dissociate 
fully the binder and at $1350{ }^{\circ} \mathrm{C}$ for 2 and $24 \mathrm{~h}$ in an electric furnace and then cooled slowly.

\subsection{Measurements}

The final sintered samples were crushed and ground using an alumina mortar and then lightly pressed into glass specimen holders. The crystalline structure of the sintered samples was examined by XRD analysis. Data collection was repeated several times with lightly pressed samples in order to ensure that the effects of preferred orientation were minimized. The XRD data of the sintered samples were collected at ambient temperature using a X-ray diffractometer (MXP, MAC Science Co. Ltd, Tokyo, Japan) under the following experimental conditions: intensity measurements were made at intervals of $0.04^{\circ}$ over the $2 \theta$ range $20^{\circ}-120^{\circ}$ using $\mathrm{Cu} K_{\alpha}$ radiation and $1^{\circ}$ divergence and scattering slits. All data sets were collected using a step-counting time of $6 \mathrm{~s}$. XRD powder data were refined and analysed by the multiphase Rietveld method (Rietveld analysis program RIETAN, Izumi, 1995) to determine the mass fractions of tetragonal and cubic phases, as well as their lattice parameters and unit-cell density.

\section{Results and discussion}

The formation of $\mathrm{BaSn}_{x} \mathrm{Ti}_{1-x} \mathrm{O}_{3}$ solid solutions for $x \leqslant 0.1$ were verified using $\mathrm{X}$-ray diffraction analyses. Fig. 1 depicts the XRD patterns for $x=0.02-0.1$ sintered at $1350^{\circ} \mathrm{C}$ for $2 \mathrm{~h}$. It was found that the 110 and 200 reflections of the cubic $\mathrm{BaSnO}_{3}$ structure became discernible under a lower tin content. However, the formation of $\mathrm{BaSn}_{x} \mathrm{Ti}_{1-x} \mathrm{O}_{3}(x \geqslant 0.1)$ sintered for $2 \mathrm{~h}$ and over the full range of compositions sintered for $24 \mathrm{~h}$ form a complete solid solution and chemical homogeneity. Some reports [10-12] have indicated that the samples prepared by a solid-state reaction method might have complicated microstructures and caused reactions and/or quenching to be incomplete in the formation region of the tetragonal phases.

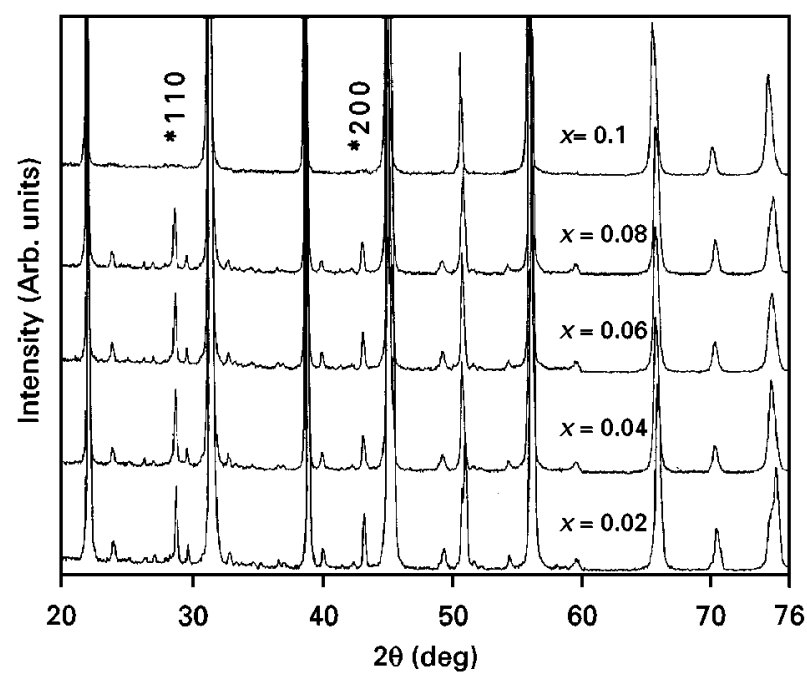

Figure 1 Powder XRD diffraction patterns of $\mathrm{BaSn}_{x} \mathrm{Ti}_{1-x} \mathrm{O}_{3}$ $(x=0.02-0.1)$ at $1350^{\circ} \mathrm{C}$ for $2 \mathrm{~h} . * 110$ and $* 200$ are reflections of the cubic $\mathrm{BaSnO}_{3}$.
Calos et al. [8] refined the lattice constants of $\mathrm{Sr}_{1-x} \mathrm{~Pb}_{x} \mathrm{TiO}_{3}, \mathrm{Ba}_{1-x} \mathrm{~Pb}_{x} \mathrm{TiO}_{3}$ and $\mathrm{Ca}_{1-x} \mathrm{~Pb}_{x} \mathrm{TiO}_{3}$ as functions of $x$, obtained from XRD and Rietveld analyses by one phase. Yoon et al. [7] calculated the structure of the $\left(\mathrm{Ba}_{0.9} \mathrm{Ca}_{0.1}\right)\left(\mathrm{Ti}_{1-x} \mathrm{Sn}_{x}\right) \mathrm{O}_{3}$ system, and reported that the $a$-axis lattice constant is elongated and the $c$-axis value is shortened as the amount of $\mathrm{SnO}_{2}$ increases, and the $a$-axis is elongated and the $c$-axis is shortened as the soaking time is lengthened. In fact, these variations of the lattice constants can be explained in terms of the phase transition from tetragonal to cubic structure due to increases in $\mathrm{SnO}_{2}$ content. The XRD patterns in Fig. 2 indicate that the sample for composition $x=0.0$ (pure $\mathrm{BaTiO}_{3}$ ) is tetragonal phase and the 301 and 310 reflection $\left(2 \theta=74^{\circ}-76^{\circ}\right)$ split into two peaks. These reflections shift to combine together in the region between $x=0.02$ and 0.08 . It has been indicated that the amounts of phase transformations from tetragonal to cubic increase with an increase in $\mathrm{BaSnO}_{3}$ content. The samples for $x \geqslant 0.1$ are the cubic phase only in the 310 reflection.

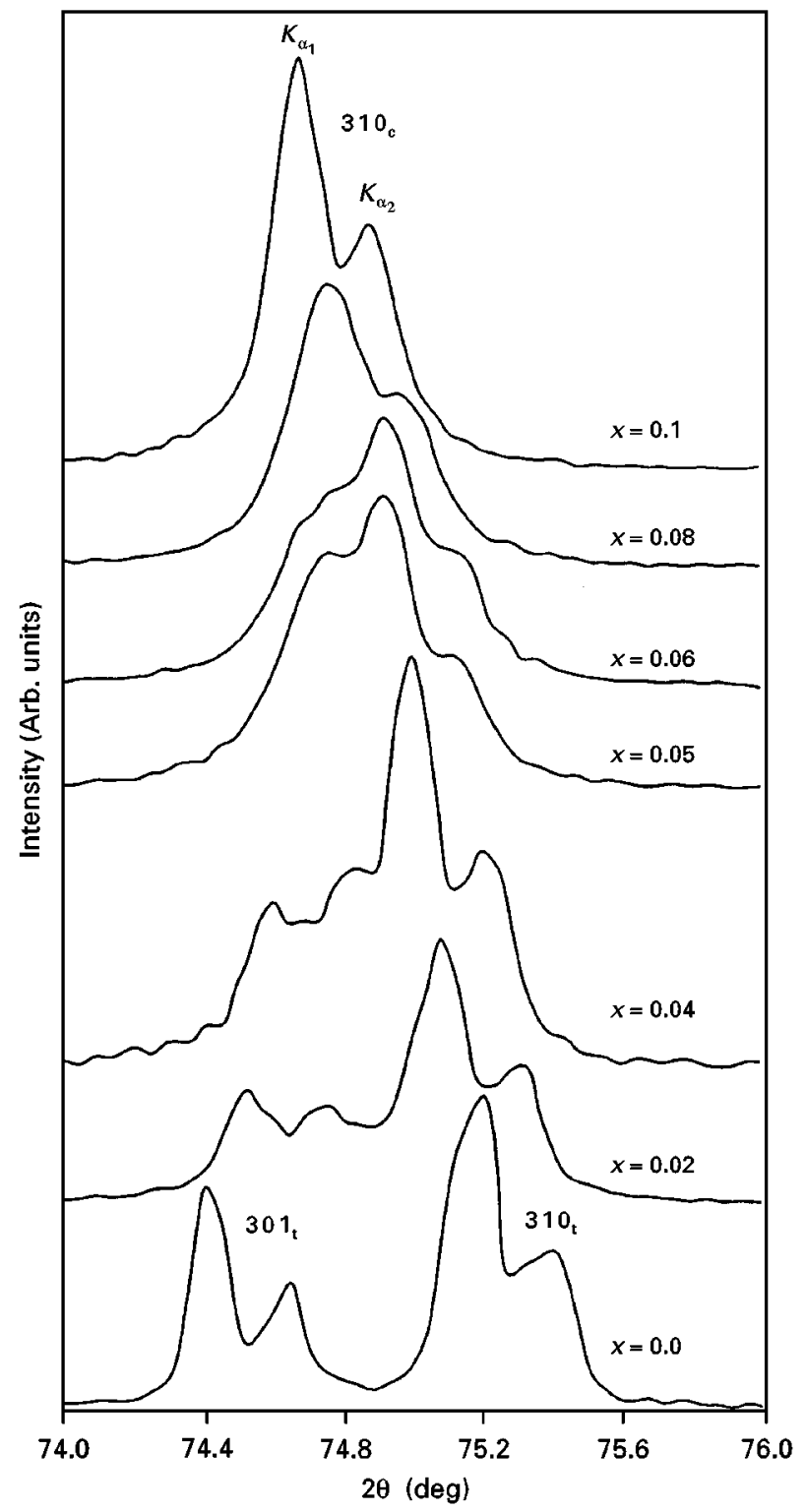

Figure 2 Powder XRD patterns of $\mathrm{BaSn}_{x} \mathrm{Ti}_{1-x} \mathrm{O}_{3}$ for $x=0.0-0.1$. The phase transformations of tetragonal to cubic phase are indicated. 
As shown in Fig. 3, the mass fractions of the different polymorphs at each content were estimated from the scale factors obtained in the final refinements, using the Equation 13

$$
X_{p}=\frac{S_{p} Z_{p} M_{p} V_{p}}{\Sigma_{q} S_{q} Z_{q} M_{q} V_{q}}
$$

where $X_{p}$ is the mass fraction of the $p$ th phase, $Z_{p}$ is the number of formula units each of mass $M_{p}$ in the unit-cell volume $V_{p}$, and $S_{p}$ is the Rietveld scale factor for the $p$ th phase. Detailed results of different contents and species of dopants from the quantitative phase analysis are shown in Fig. 3. The amounts of tetragonal phase decrease when the contents of $\mathrm{BaSnO}_{3}$ increase. On the other hand, the amounts of cubic phase increase with increasing $\mathrm{BaSnO}_{3}$ content and $\mathrm{Ti}^{4+}$ ions are replaced by $\mathrm{Sn}^{4+}$ ions over the range of the solid solubility of barium titanate ceramics. In the compositional region of $x \geqslant 0.1$, the crystal structure becomes identical to the fully cubic phase.

Fig. 4 shows the lattice parameters of the tetragonal and cubic phases in the $\mathrm{BaSn}_{x} \mathrm{Ti}_{1-x} \mathrm{O}_{3}$ system at room temperature. The lattice parameters of the tetragonal phases containing from $x=0.02-0.08$ showed linear relations, and the $a$-axis and $c$-axis approach each other rapidly in samples ranging from $x=0.08-0.1$. The lattice parameters of cubic phases in the system produced linear relations with $\mathrm{BaSnO}_{3}$ content for all regions. This behaviour of the lattice parameters of the cubic phase varies continuously with $\mathrm{BaSnO}_{3}$. This suggests that $\mathrm{BaSnO}_{3}$ and $\mathrm{BaTiO}_{3}$ form a complete solid solution and chemical homogeneity in the cubic phase region, where the $\mathrm{Ti}^{4+}$ ion is substituted by the $\mathrm{Sn}^{4+}$ ion.

Fig. 5 shows the tetragonalities (axial ratio $c / a$ ) of samples containing $\mathrm{BaSnO}_{3}$. The tetragonality of $\mathrm{BaSn}_{x} \mathrm{Ti}_{1-x} \mathrm{O}_{3}$ from $x=0.02-0.1$ vary continuously. The value of 1.008 is the tetragonality of the tetragonal phase for pure $\mathrm{BaTiO}_{3}$ obtained by the extrapolation

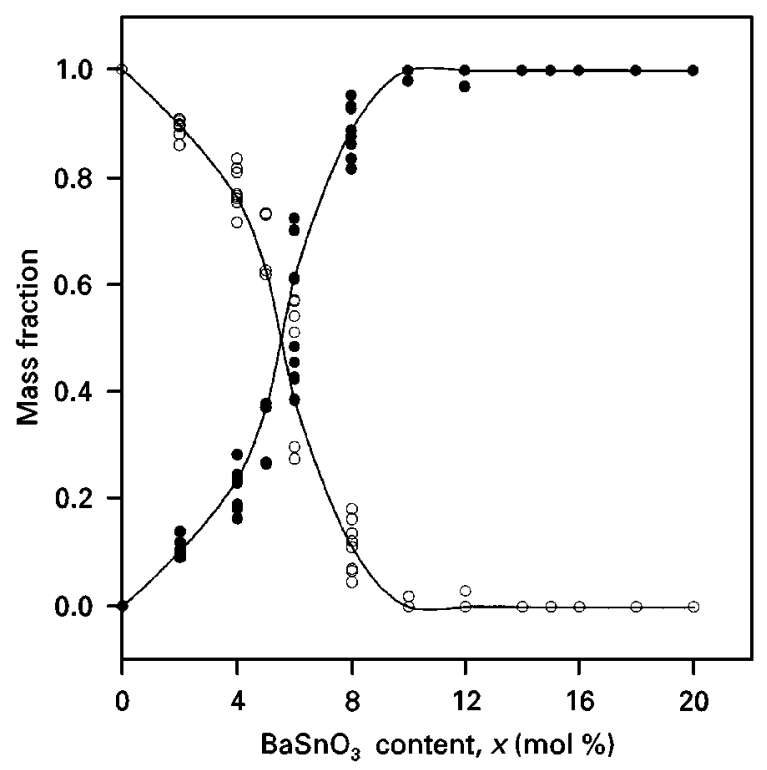

Figure 3 Relationships between the mass fraction of $(\mathbf{O})$ cubic and (O) tetragonal phase and the $\mathrm{BaSnO}_{3}$ content.

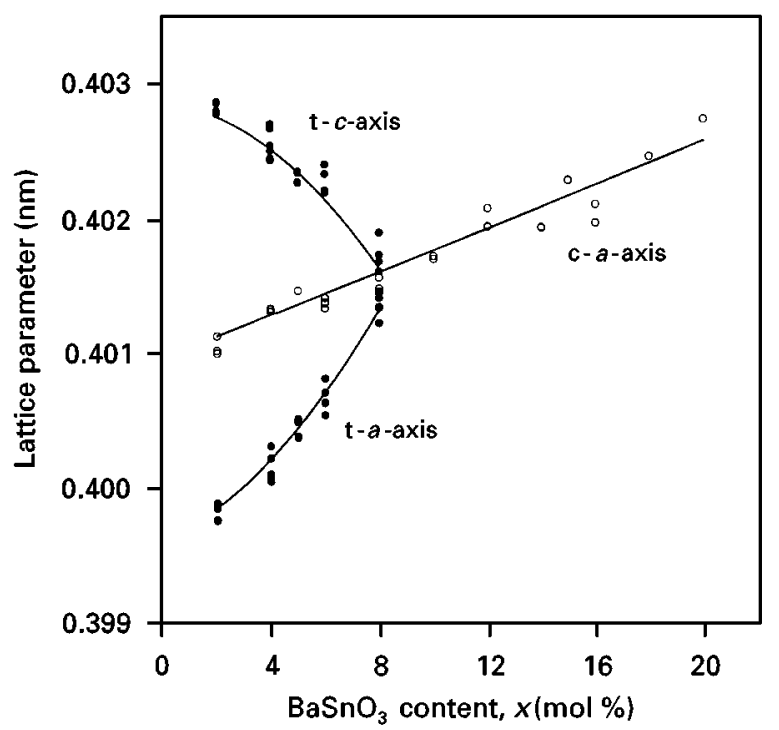

Figure 4 Relationship between the lattice parameters and the $\mathrm{BaSnO}_{3}$ content. (O) cubic phase, (O) tetragonal phase.

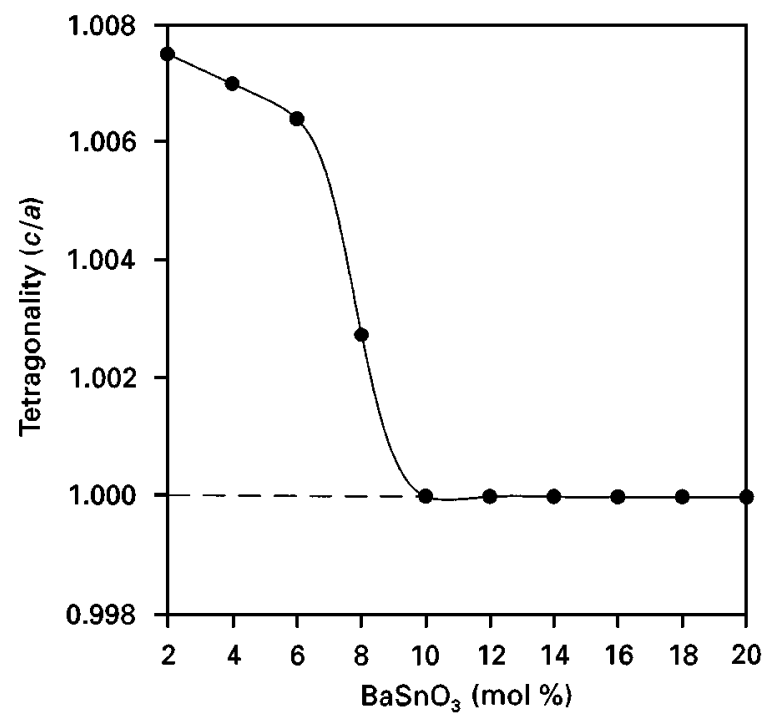

Figure 5 Relationship between the $\mathrm{BaSnO}_{3}$ composition and tetragonality (axial ratio $c / a$ ).

method. Similar results have been reported by Mitsui and Westphal [14] and Swanson and Fuyat [15]. Tetragonality decreases with the $\mathrm{BaSnO}_{3}$ content, and then rapidly approaches 1.0 of the cubic phase in the compositional range from $x=0.06-0.1$.

Fig. $6 a$ and $b$ show the linear relations between the content of $\mathrm{BaSnO}_{3}$ and the density of the unit cell of cubic and tetragonal phases, respectively. The unit-cell density is calculated from the atomic weight in the unit cell, and the lattice parameters are calculated by Rietveld refinement. It revealed that the density of the unit cell is dependent on both atomic weight and the dopant content.

\section{Conclusions}

1. When the amount of $\mathrm{BaSnO}_{3}$ increases in the $\mathrm{BaSn}_{x} \mathrm{Ti}_{1-x} \mathrm{O}_{3}$ system, the crystal structure will be transformed from a tetragonal to cubic phase. The 

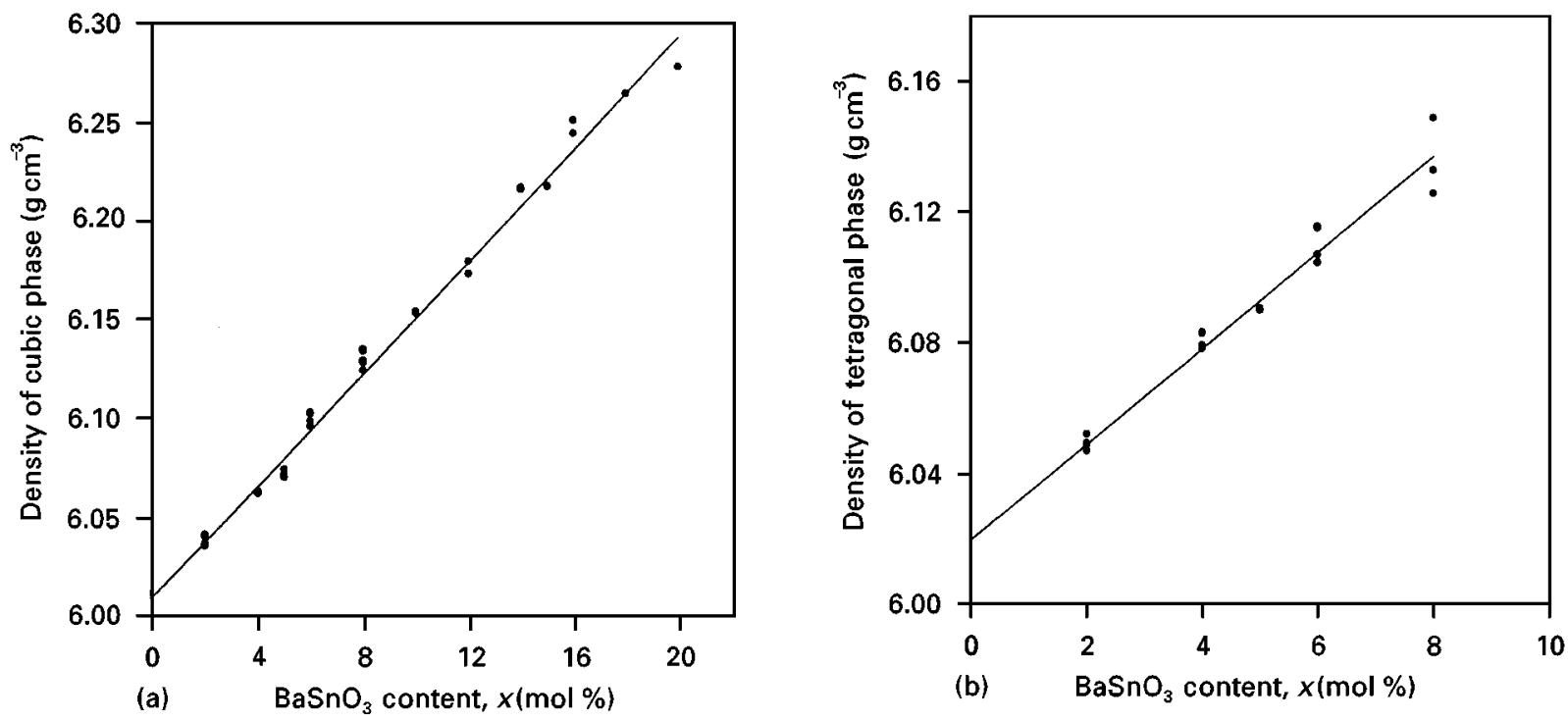

Figure 6 Relationships between the $\mathrm{BaSnO}_{3}$ content and the density of (a) the cubic phase, and (b) the tetragonal phase.

tetragonal and cubic phases will coexist in the regions from $x=0.0-0.1$.

2. A second phase will exist in the lower content of $\mathrm{BaSnO}_{3}$, because the samples prepared by the solidstate reactions method might have complicated microstructures and caused reactions and/or quenching to be incomplete in the formation region of the tetragonal phases.

3. As the substitution of $\mathrm{Sn}^{4+}$ ions for $\mathrm{Ti}^{4+}$ ions increases, the Curie temperature shifts to a lower temperature, essentially influenced by the phase transition from tetragonal to cubic structure.

\section{References}

1. A. L. GRAY and J. M. HERBERT, ACUSTICA 6 (1956) 229.

2. R. J. LOCKHART and J. MAgder, J. Am. Ceram. Soc. 49 (1966) 299.

3. G. H. JONKER and W. KWESTOO, ibid. 41 (1958) 390.

4. D. HENNINGS and H. SCHREINMACHER, Mater. Res. Bull. 12 (1977) 1221.

5. G. A. SMOLENSK Y, J. Inorg. Chem. Moscow 1 (1956) 1402.

6. O. DREXLER and B. R. SCHAT, "Science of Ceramic", Vol. 1 (Academic Press, London, New York, 1967).
7. K. H. YOON, J. H. KIM, K. H. JO, H. I. SONG, S. O YOON and C. S. KIM, J. Mater. Sci. 23 (1988) 61.

8. N. CALOS, J. FORRESTER, T. J. White, P. R. GRAVES and S. MYHRA, ibid. 30 (1995) 4930.

9. V. S. TIWARI, N. Sin G H and D. PANDEY, J. Am. Ceram. Soc. 77 (1994) 1813.

10. L. LANTERI, A. H. HEUER and T. E. MitCHELL, "Advances in Ceramics", Vol. 12, "Science and Technology of Zirconia II", edited by N. Claussen, M. Rhule and A. H. Heuer (American Ceramic Society, Columbus, OH, 1984) p. 118.

11. R. A. Miller, J. L. SMIALEK and R. G. GARILICK, "Advances in Ceramics", Vol. 3, "Science and Technology of Zirconia I", edited by A. H. Heuer and L. W. Hobbs (American Ceramic Society, Columbus, OH, 1981) p. 241.

12. T. SAKUMA, Y. Y O SHIZA W A and H. SUTO, J. Mater. Sci. 20 (1985) 2399.

13. R. J. HILL and C. J. HOW A R D, J. Appl. Crystallogr. 20 (1987) 467.

14. T. Mitsui and W. B. Westphal, Phys. Rev. 124 (1961) 1354.

15. H. E. SWANSON and R. K. FUYAT, National Bureau of Standards, Circular 539 (National Bureau of Standards, Washington, DC, 1954) p. 45.

Received 29 April

and accepted 27 November 1997 